\title{
Protective Effect of Ginsenoside Rg1 on Oxidative Damage Induced by Hydrogen Peroxide in Chicken Splenic Lymphocytes
}

\author{
Shicheng Bi, Xiaodan Ma (D), Yuemin Wang, Xiaoqing Chi, Yong Zhang, Wei Xu(D), \\ and Songhua $\mathrm{Hu}(\mathbb{D}$ \\ Department of Veterinary Medicine, College of Animal Sciences, Zhejiang University, Hangzhou, Zhejiang 310058, China \\ Correspondence should be addressed to Songhua Hu; songhua@zju.edu.cn
}

Received 17 December 2018; Accepted 4 March 2019; Published 18 April 2019

Academic Editor: Laura Bravo

Copyright (C) 2019 Shicheng Bi et al. This is an open access article distributed under the Creative Commons Attribution License, which permits unrestricted use, distribution, and reproduction in any medium, provided the original work is properly cited.

\begin{abstract}
Previous investigation showed that ginsenoside Rg1 (Rg1) extracted from Panax ginseng C.A. Mey has antioxidative effect on oxidative stress in chickens. The present study was designed to investigate the protective effects of $\operatorname{Rg} 1$ on chicken lymphocytes against hydrogen peroxide-induced oxidative stress and the potential mechanisms. Cell viability, apoptotic cells, malondialdehyde, activity of superoxide dismutase, mitochondrial membrane potential, and $\left[\mathrm{Ca}^{2+}\right] \mathrm{i}$ concentration were measured, and transcriptome analysis and quantitative real-time polymerase chain reaction were used to investigate the effect of Rg1 on gene expression of the cells. The results showed that treatment of lymphocytes with $\mathrm{H}_{2} \mathrm{O}_{2}$ induced oxidative stress and apoptosis. However, pretreatment of the cells with $\mathrm{Rg} 1$ dramatically enhanced cell viability, reduced apoptotic cells, and decreased oxidative stress induced by $\mathrm{H}_{2} \mathrm{O}_{2}$. In addition, $\mathrm{Rg} 1$ reduced these $\mathrm{H}_{2} \mathrm{O}_{2}$-dependent decreases in mitochondrial membrane potential and reversed $\left[\mathrm{Ca}^{2+}\right] \mathrm{i}$ overload. Transcriptome analysis showed that 323 genes were downregulated and 105 genes were upregulated in Rg1-treated cells. The differentially expressed genes were involved in Toll-like receptors, peroxisome proliferator-activated receptor signaling pathway, and cytokine-cytokine receptor interaction. The present study indicated that Rg1 may act as an antioxidative agent to protect cell damage caused by oxidative stress via regulating expression of genes such as RELT, EDA2R, and TLR4.
\end{abstract}

\section{Introduction}

In the modern poultry industry, animals usually suffer from highly condensed population, contaminated feed, pollutant air, and inappropriate management, which may result in oxidative stress and lead to immunity dysfunction [1]. For example, consumption of aflatoxin B1 diets was reported to significantly inhibit the immune responses of chickens to vaccination against Newcastle disease [2]. Another study suggested that aflatoxin B1 increases oxidative stress, induces excessive apoptosis of lymphocytes in the spleen and bursa, and decreases the immunity $[3,4]$. Environmental pollutants such as cadmium and $\mathrm{H}_{2} \mathrm{~S}$ were reported to be toxic on the spleen or other organs of chickens, have negative effect on the immunity, cause oxidative stress, and consequently exacerbate disharmony of the immune and antioxidative systems $[5,6]$. Though the exact mechanism is complicated, unbalance between reactive oxygen species
(ROS) production and elimination has been widely implicated for the damage of the immune system and immunodeficiency $[7,8]$. As a peripheral immune organ, the spleen is one of the principal sites for priming of the primary immune responses [9]. Accumulating literatures have reported that oxidative stress is associated with suppressed immune function in animals $[10,11]$.

Previous investigation showed that saponins extracted from the stem and leaf of Panax ginseng C.A. Mey (GSLS) have antistress effect on chickens [12]. More than 30 ginsenosides have been identified from the herb as of yet, and ginsenoside $\operatorname{Rg} 1$ ( $\operatorname{Rg} 1)$, a steroidal saponin, is one of the active constituents in GSLS $[13,14]$. The saponin was found to display antioxidant activity in mice and human $[15,16]$. It was reported that $\operatorname{Rg} 1$ had an antioxidant effect by alleviating oxidative damage in a cardiomyocyte hypoxia/reoxygenation $(\mathrm{H} / \mathrm{R})$ model [17]. Liu et al. showed that Rg1 can prevent apoptosis and ROS production in oxidative modification of 
human umbilical cord blood-derived stromal cells induced by tert-butyl hydroperoxide [18]. Very recently, oral administration of $\mathrm{Rg} 1$ was reported to have effects of antioxidative stress and immunomodulation in chickens [19].

In 2017, the Agricultural Ministry of China issued a certificate approving the product made from GSLS to be used in poultry. However, very few reports have been found regarding the mechanisms underlying the antistress in chickens. The present study was designed to investigate the protective effects of Rg1 on chicken splenic lymphocytes treated with hydrogen peroxide $\left(\mathrm{H}_{2} \mathrm{O}_{2}\right) \cdot \mathrm{H}_{2} \mathrm{O}_{2}$ is often experimentally used to stimulate production of ROS in vitro [20,21]. RNA sequencing (RNA-seq) is a technique to quantify differentially expressed genes involved in various biological processes. The possible molecular mechanisms were explored at the transcriptome level by RNA-seq analysis, and the DEGs of interest were validated by quantitative real-time polymerase chain reaction (RT-qPCR).

\section{Materials and Methods}

2.1. Preparation of Chicken Splenic Lymphocytes. The procedures on handling animals in this experiment were approved by the Institutional Animal Care and Use Committee of Zhejiang University. The process was mainly performed as previously described [22]. Briefly, the spleens were dissected from $30 \mathrm{~d}$ old Sanhuang broilers (female) (Ningbo Zhenning Stock Breeding Inc., Ningbo, China) and polished to homogenate. Single cell suspension was obtained by gently pushing the homogenate through a $70 \mu \mathrm{m}$ sterile plastic mesh. Cells were washed twice and then layered over equivalent lymphocyte separation medium (Tian Jin Hao Yang Biological Manufacture Co. Ltd., Tianjin, China). The suspension was centrifuged at $2,000 \times \mathrm{g}$ for $15 \mathrm{~min}$ at room temperature, and a white interface was obtained. Then, the cells were washed twice and cultured in RPMI 1640 (Genom Biotech Co., Hangzhou, China) containing HEPES and $2 \mathrm{mM}$ glutamine, supplemented with 10\% FBS (Sijiqing Co., Hangzhou, China). Splenic lymphocyte density was adjusted to $5 \times 10^{6}$ cells $/ \mathrm{mL}$, and the survival rate of the freshly obtained cells was more than 95\% (trypan blue exclusion test) [23].

2.2. Cell Treatment. Cells were seeded in 6-well plates $\left(5 \times 10^{6}\right.$ per well), added with $\mathrm{Rg} 1$ solution (Puruifa, Chengdu, China) at final concentrations of $0,50,70$, and $90 \mu \mathrm{g} / \mathrm{mL}$, respectively, and then cultured for $24 \mathrm{~h}$. The concentrations of ginsenoside Rg1 were used based on the previous study [24]. After that, cells were washed twice with PBS and incubated in media containing $\mathrm{H}_{2} \mathrm{O}_{2}(100 \mu \mathrm{mol} / \mathrm{L})$ for an additional $4 \mathrm{~h}$. Cells treated with $\mathrm{H}_{2} \mathrm{O}_{2}$ only were used as a model, and cells without any treatment were used as a control (Table 1). Finally, the cells were collected for analyses of redox parameters, cell viability, cell apoptosis, mitochondria transmembrane potential, and $\left[\mathrm{Ca}^{2+}\right] \mathrm{i}$ concentration.

2.3. Biochemical Determinations. The method was used as previously described [21]. To release the intracellular content, $1 \mathrm{~mL}$ of cell suspension $\left(5 \times 10^{6}\right.$ cells $)$ was sonicated and centrifuged at $1,000 \times \mathrm{g}$ for $5 \mathrm{~min}$. The content of the cell
TABLE 1: Experimental design.

\begin{tabular}{llcc}
\hline Groups & $n$ & $\mathrm{H}_{2} \mathrm{O}_{2}(\mu \mathrm{mol} / \mathrm{L})$ & $\operatorname{Rg} 1(\mu \mathrm{g} / \mathrm{mL})$ \\
\hline Control & 6 & 0 & 0 \\
Mode & 6 & 100 & 0 \\
Rg1-50 & 6 & 100 & 50 \\
Rg1-70 & 6 & 100 & 70 \\
Rg1-90 & 6 & 100 & 90 \\
\hline
\end{tabular}

proteins was measured with a bicinchoninic acid kit (BCA) (Beyotime Co., Jiangsu, China). Content of malondialdehyde (MDA) and activity of superoxide dismutase (SOD) were measured with spectrophotometric assay kits (Nanjing Jiancheng Institute of Bioengineering and Technology, Nanjing, China). All samples were analyzed in triplicate.

2.4. Determination of Intracellular ROS Production. ROS generation was measured by a reactive oxygen species assay kit (Yeasen Biotech Co. Ltd., Shanghai, China) with 2,7-dichlorodihydrofluorescein diacetate (DCFH-DA) as a fluorescent probe [25]. Cells $\left(1 \times 10^{5}\right)$ were suspended in $500 \mu \mathrm{L}$ of DCFH-DA ( $1: 2,000$ dilutions) with incubation at $37^{\circ} \mathrm{C}$ for $30 \mathrm{~min}$. The culture was centrifuged at $1,000 \times \mathrm{g}$ for $5 \mathrm{~min}$, and the supernatant was discarded. Then, cells were washed twice with PBS and used for flow cytometric (FCM, BD FACSCalibur) analysis. The mean fluorescent intensity (MFI) of intracellular 2,7-dichlorodihydrofluorescein (DCF) was detected by FCM, and the data were analyzed using FlowJo V10 software.

2.5. Cell Viability. Live cells were measured by the 3-(4,5dimethyl-2-thiazolyl)-2,5-diphenyl-2-H-tetrazolium bromide (MTT) assay (Solarbio Co., Beijing, China) using absorbance of formazan in cell lysates according to previous description with modification [26]. Briefly, cells in 96-well plates $\left(5 \times 10^{4}\right.$ cells/well $)$ were incubated for $24 \mathrm{~h}$ with $\mathrm{Rg} 1$ at final concentrations of $0,50,70$, and $90 \mu \mathrm{g} / \mathrm{mL}$, respectively, and then centrifuged at $2,000 \times \mathrm{g}$ for $10 \mathrm{~min}$. Then, cells were washed twice with PBS and exposed to fresh media containing $\mathrm{H}_{2} \mathrm{O}_{2}(100 \mu \mathrm{mol} / \mathrm{L})$ for an additional $4 \mathrm{~h}$. Cells treated with $\mathrm{H}_{2} \mathrm{O}_{2}$ only were used as the model, and cells without any treatment were used as the control. After that, cells in each well were incubated with $5 \mathrm{mg} / \mathrm{mL}$ MTT for $4 \mathrm{~h}$. Then, the plates were centrifuged at $1,000 \times \mathrm{g}$ for $10 \mathrm{~min}$, and the MTT formazan was solubilized in $150 \mu \mathrm{L}$ dimethyl sulfoxide. The optical density (OD) was read at $570 \mathrm{~nm}$. All tests were carried out in triplicate.

2.6. Quantification of Cell Apoptosis. Apoptosis was investigated using an Annexin V-FITC Apoptosis Detection kit (BD Biosciences, San Jose, CA, USA). Cells $\left(1 \times 10^{5}\right)$ were suspended in $195 \mu \mathrm{L}$ of specific binding buffer with $5 \mu \mathrm{L}$ Annexin V-FITC and incubated for $10 \mathrm{~min}$ at $25^{\circ} \mathrm{C}$. Then, the cells were washed twice with phosphate-buffered saline (PBS) and resuspended in $190 \mu \mathrm{L}$ binding buffer with $10 \mu \mathrm{L}$ propidium iodide (PI) [27]. Fluorescence in cells was detected by FCM, and the data were analyzed using FlowJo 
V10 software. Annexin V+/PI- cells were considered as early apoptotic cells.

2.7. Measurement of Mitochondrial Membrane Potential. 5,5' $, 6,6^{\prime}$-Tetrachloro-1,1 $1^{\prime}, 3,3^{\prime}$-tetraethyl-imidacarbocyanine io dide (JC-1) is able to enter mitochondria and is widely used as a mitochondrial membrane potential-sensitive dye [28]. The detection was performed according to a manufacturer's protocol (Solarbio Co., Beijing, China). In brief, cells $\left(1 \times 10^{5}\right)$ were incubated with JC- $1(5 \mu \mathrm{g} / \mathrm{mL})$ for $20 \mathrm{~min}$ at $37^{\circ} \mathrm{C}$. After washing twice in PBS, JC-1 polymer MFI and monomer MFI were assayed by FCM within $30 \mathrm{~min}$ and analyzed using FlowJo V10 software. Mitochondrial depolarization was presented by a reduction in the polymer MFI/monomer MFI.

2.8. Observation and Analysis of $\left[\mathrm{Ca}^{2+}\right] i .\left[\mathrm{Ca}^{2+}\right] \mathrm{i}$ in lymphocytes were determined as previously reported [22, 29]. Briefly, cells $\left(1 \times 10^{5}\right)$ were incubated with Fluo-3/AM $(5 \mu \mathrm{M})$ (Solarbio Co., Beijing, China) at $37^{\circ} \mathrm{C}$ for $30 \mathrm{~min}$. After washing with PBS, cells were observed, and the images were acquired using a fluorescence microscopy equipped with an FITC filter (Nikon Ti-FL; Nikon Cooperation, Japan). For quantitative analysis, the fluorescent signals reflecting the $\left[\mathrm{Ca}^{2+}\right] \mathrm{i}$ level were measured by FCM, and the data were analyzed using FlowJo V10 software. Intracellular $\left[\mathrm{Ca}^{2+}\right]$ i was reflected by Fluo-3 fluorescent intensity.

2.9. Transcriptome Analysis. Each of the three samples from the model and Rg1 groups was used for the RNA-seq. RNAiso $^{\mathrm{TM}}$ Plus (Takara, Dalian, China) was used to isolate the total RNA from cells, according to the manufacturer's instructions. A NanoPhotometer ${ }^{\circledR}$ spectrophotometer (Implen, CA, USA) was employed to determine the RNA purity [30]. A RNA 6000 Nano Assay Kit was employed to check RNA integrity on the Bioanalyzer 2100 system (Agilent Technologies, CA, USA). Transcriptome sequencing, sequence assembly, and data analysis are provided by Novogene Bioinformatics Technology Co. Ltd. (Beijing, China). A total of $2 \mu \mathrm{g}$ RNA from each sample was employed to construct libraries with a NEBNext ${ }^{\circledR}$ Ultra $^{\mathrm{TM}}$ RNA Library Prep Kit for Illumina ${ }^{\circledR}$ (NEB, USA). In brief, poly-T oligoattached magnetic beads were used to extract mRNA from total RNA [31]. NEBNext First Strand Synthesis Reaction Buffer (5x) was used to perform fragmentation. Random hexamer primer and M-MuLV Reverse Transcriptase (RNase $\mathrm{H}^{-}$) were used to synthesize first-strand cDNA. Next, DNA polymerase I and RNase $\mathrm{H}$ were used to synthesize second-strand cDNA [32]. After that, TruSeq PE Cluster Kit v3-cBot-HS (Illumina) was employed to carry out the cluster of the index-coded samples [33]. Then, the sequencing was executed on an Illumina platform, and $150 \mathrm{bp}$ paired-end reads were produced. Reference genome and gene model annotation files were downloaded from the genome website (ftp://ftp.ncbi.nlm.nih.gov/genomes/all/ GCF/000/002/315/GCF_000002315.4_Gallus_gallus-5.0/GC F_000002315.4_Gallus_gallus-5.0_genomic.fna.gz). HISAT2 (v2.0.5) was used to build the index of the reference genome, and paired-end clean reads were aligned to the reference genome (ftp://ftp.ncbi.nlm.nih.gov/genomes/all/ GCF/000/002/315/GCF_000002315.4_Gallus_gallus-5.0/GC F_000002315.4_Gallus_gallus-5.0_genomic.gff.gz). HTSeq v0.6.0 was used to count the reads mapped to each gene in samples, and reads per kilobase transcriptome per million mapped reads (RPKM) of each gene were then calculated to estimate the expression level of genes in each sample [34]. The DESeq R (1.16.1) package was selected to investigate the differential expression between the model group and the Rg1 group. A model of DESeq based on the negative binomial distribution was used to determine differential expression genes (DEGs) [35]. The $P$ value was assigned to each gene. Genes with $P<0.05$ and fold change $\geq 1.3$ were defined as DEGs [36-38]. A clusterProfiler R package was used to perform Gene Ontology (GO) enrichment analysis and to test the statistical enrichment of differential expression genes in the Kyoto encyclopedia of genes and genomes (KEGG) pathways. GO terms and KEGG terms with $P$ value less than 0.05 were considered significantly enriched by DEGs $[39,40]$.

2.10. Real-Time Quantitative PCR Validation. Five DEGs that were upregulated and twelve DEGs that were downregulated in the comparison of $\mathrm{Rg} 1$ vs. the model were selected to validate the transcriptome sequencing results using RTqPCR. PrimeScript ${ }^{\mathrm{TM}}$ RT Master Mix (Takara, Dalian, China) was used to convert RNA into CDNA on a $\mathrm{T} 100^{\mathrm{TM}}$ thermal cycler (Bio-Rad, USA) [35]. Sequences of primers used for RT-qPCR were designed using the NCBI primer designing tool (http://www.ncbi.nlm.nih.gov/tools/primer-blast/) and provided in Supplementary Materials: Table S3. The chicken $\beta$-actin was served as the internal control gene. RT-qPCR with SYBR ${ }^{\circledR}$ Premix Ex Taq ${ }^{\mathrm{TM}}$ II (Tli RNase H Plus) (Takara, Dalian, China) on selected genes was carried out on a Multiple Real-Time PCR System (Bio-Rad, USA). A relative quantitative method $\left(2^{-\Delta \Delta \mathrm{CT}}\right)$ was employed to evaluate the quantitative variation [41]. All samples were analyzed in triplicate.

2.11. Statistical Analysis. The data were analyzed with oneway ANOVA of SPSS 22.0 (IBM), and the results were expressed as mean \pm standard error (S.E.). Duncan's test was used to evaluate the differences among various groups. $P<0.05$ or $<0.01$ was considered statistically significant. $\mathrm{R}$ software (1.16.1) was used to assess results from RNA-seq.

\section{Results}

3.1. Effect of Rg1 on the Redox State and Cell Viability. Figure 1(a) showed that cells treated differently had different intracellular DCF fluorescence intensities. Figure 1(b) showed that cells treated with $\mathrm{H}_{2} \mathrm{O}_{2}$ (model) had a significantly higher intracellular ROS level than the cells without treatment (control) $(P<0.01)$. However, treatment with $\operatorname{Rg} 1(90 \mu \mathrm{g} / \mathrm{mL})$ significantly reduced intracellular ROS production when compared with the model $(P<0.05)$. Figures $1(c)$ and $1(d)$ showed that cells treated with $\mathrm{H}_{2} \mathrm{O}_{2}$ (model) had significantly higher MDA $(P<0.05)$ and lower T-SOD production $(P<0.05)$ than the cells without treatment (control). Meanwhile, treatment with Rg1 (70 and 


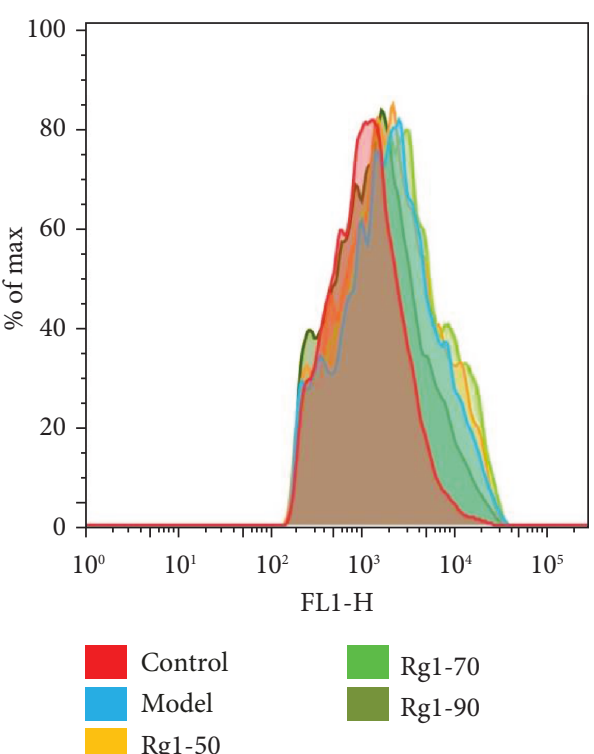

(a)

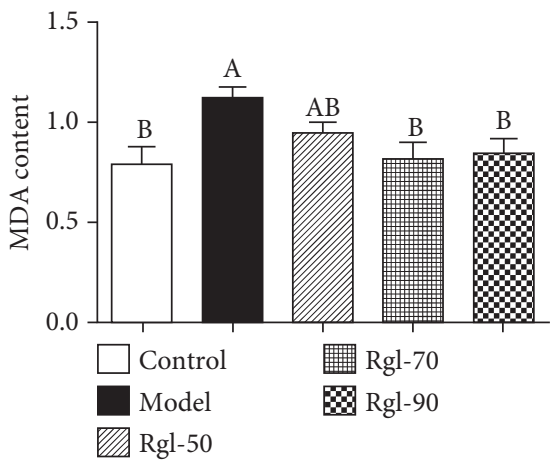

(c)

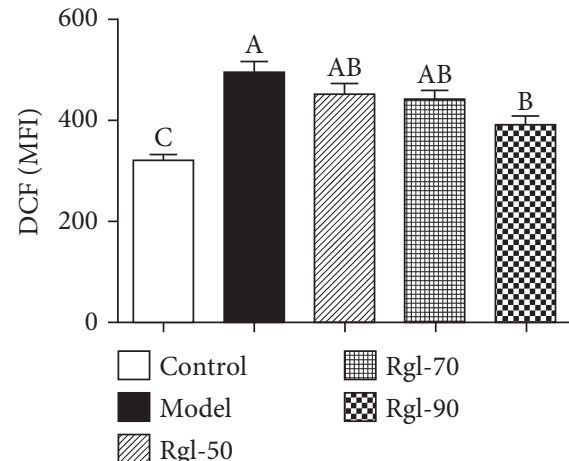

(b)

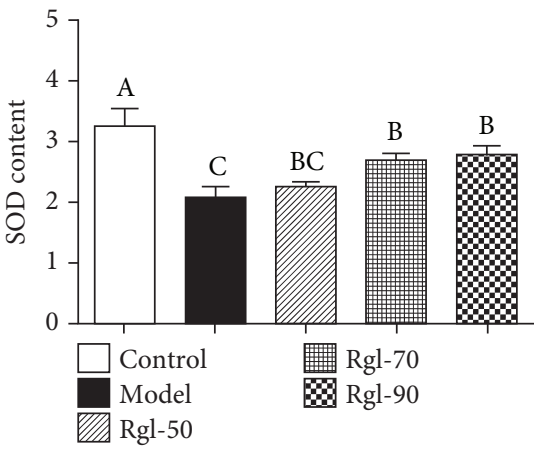

(d)

Figure 1: Effect of $\operatorname{Rg} 1$ on the redox state within cells. Cells $\left(5 \times 10^{6}\right)$ were treated with $\operatorname{Rg} 1(0,50,70$, and $90 \mu \mathrm{g} / \mathrm{mL})$ for $24 \mathrm{~h} \mathrm{first} \mathrm{and} \mathrm{then}$ incubated in media with (model) or without (control) $\mathrm{H}_{2} \mathrm{O}_{2}(100 \mu \mathrm{mol} / \mathrm{L})$ for an additional $4 \mathrm{~h}$. The original tracings showing the (a) DCF fluorescence intensity (intracellular ROS), (b) mean fluorescence intensity (MFI), (c) MDA content, and (d) SOD activities were determined as described in the text. All data are presented as mean \pm S.E. $(n=6)$. Bars with different letters were significantly different $(P<0.05)$.

$90 \mu \mathrm{g} / \mathrm{mL}$ ) significantly decreased MDA and increased TSOD production $(P<0.05)$ when compared to the model. Figure 2 showed that cells treated with $\mathrm{H}_{2} \mathrm{O}_{2}$ (model) had a significantly lower cell viability than the control $(P<0.01)$, and treatment with $\operatorname{Rg} 1(90 \mu \mathrm{g} / \mathrm{mL})$ significantly enhanced cell viability when compared to the model $(P<0.05)$.

3.2. Cell Apoptosis. Figures 3(a)-3(e) showed that cells treated differently had different percentages of early apoptotic cells (Annexin V positive and PI negative). Figure 3(f) showed that cells treated with $\mathrm{H}_{2} \mathrm{O}_{2}$ (model) had significantly increased percentage of early apoptotic cells than the control $(P<0.01)$, and treatment with $\operatorname{Rg} 1(70$ and $90 \mu \mathrm{g} / \mathrm{mL})$ significantly decreased percentage of early apoptotic cells when compared to the model $(P<0.05)$.

3.3. Mitochondrial Membrane Potential. Figures 4(a)-4(e) displayed that cells treated differently had different JC-1

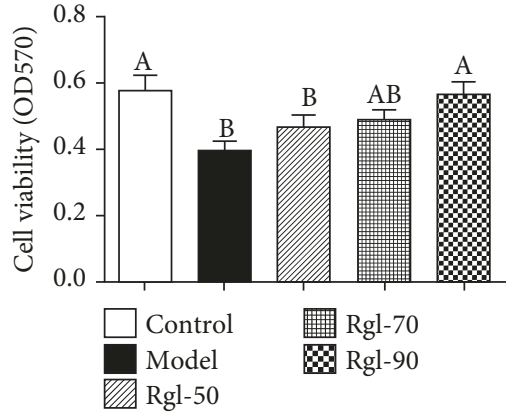

Figure 2: Effect of Rg1 on cell viability. Cells $\left(5 \times 10^{5}\right)$ were treated with $\operatorname{Rg} 1(0,50,70$, and $90 \mu \mathrm{g} / \mathrm{mL})$ for $24 \mathrm{~h}$ first and then incubated in media with (model) or without (control) $\mathrm{H}_{2} \mathrm{O}_{2}(100 \mu \mathrm{mol} / \mathrm{L})$ for an additional $4 \mathrm{~h}$. Live cells were measured by the MTT assay using absorbance of formazan in cell lysates. All data are presented as mean \pm S.E. $(n=6)$. Bars with different letters were significantly different $(P<0.05)$. 


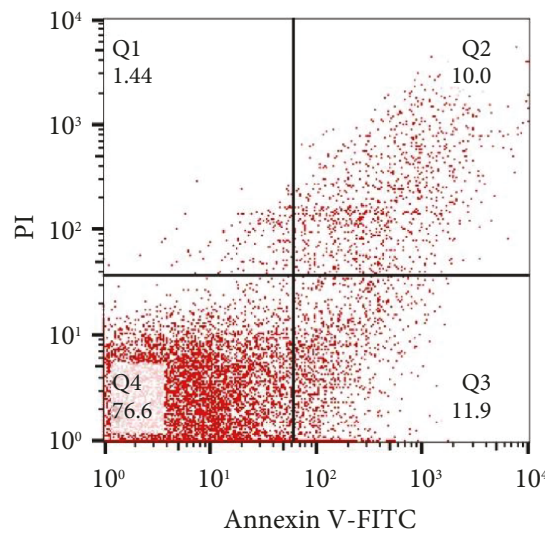

(a)

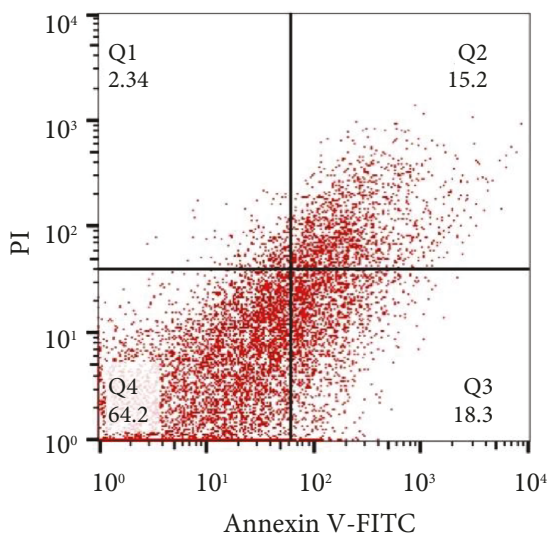

(c)

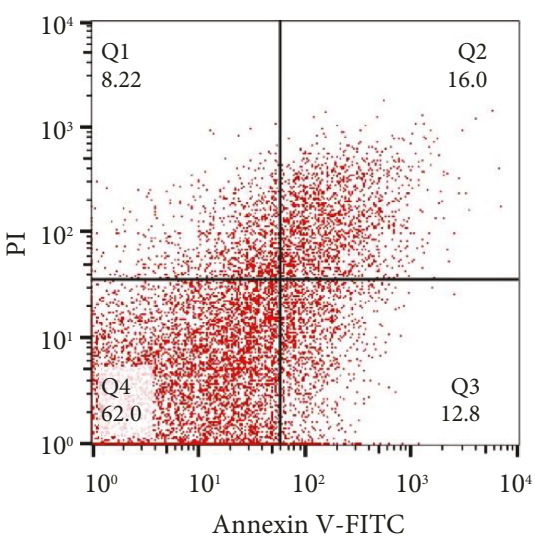

(e)

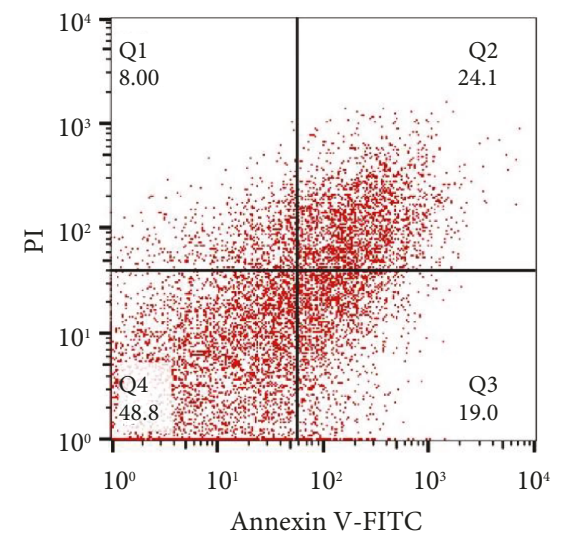

(b)

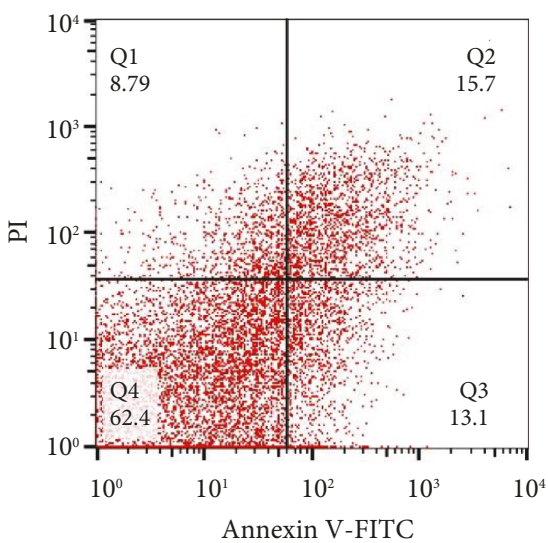

(d)

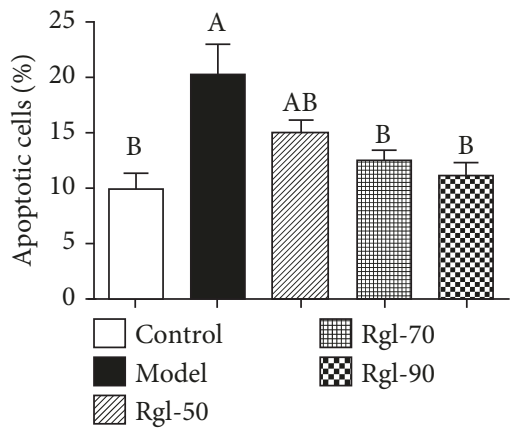

(f)

Figure 3: Effect of $\operatorname{Rg} 1$ on apoptosis of cells. Cells $\left(5 \times 10^{6}\right)$ were treated with $\operatorname{Rg} 1(0,50,70$, and $90 \mu \mathrm{g} / \mathrm{mL})$ for $24 \mathrm{~h}$ first and then incubated in media with (model) or without (control) $\mathrm{H}_{2} \mathrm{O}_{2}(100 \mu \mathrm{mol} / \mathrm{L}$ ) for an additional $4 \mathrm{~h}$. Apoptotic cells (Annexin V+/PI-) were discriminated by FCM analysis: (a) control group; (b) model group; (c) $50 \mu \mathrm{g} / \mathrm{mL}$ Rg1 group; (d) $70 \mu \mathrm{g} / \mathrm{mL}$ Rg1 group; (e) $90 \mu \mathrm{g} / \mathrm{mL}$ Rg1 group; (f) bar diagram representing apoptotic cell populations. All data are presented as mean \pm S.E. $(n=6)$. Bars with different letters were significantly different $(P<0.05)$.

polymer/monomer MFI. Figure 4(f) showed that cells treated with $\mathrm{H}_{2} \mathrm{O}_{2}$ (model) had significantly decreased JC-1 polymer/monomer MFI than the control $(P<0.01)$. Interestingly, treatment with $\operatorname{Rg} 1$ (70 and $90 \mu \mathrm{g} / \mathrm{mL}$ ) significantly increased this parameter when compared to the model $(P<0.01)$.
3.4. $\left[\mathrm{Ca}^{2+}\right] i$. The green fluorescence intensity represented the $\left[\mathrm{Ca}^{2+}\right] \mathrm{i}$ concentrations in lymphocytes. Figures 5(a)-5(e) showed that cells treated differently had different fluorescence intensities. We also detected fluorescence intensity by FCM. The results implied a similar trend. Figure 5(f) showed that cells treated with $\mathrm{H}_{2} \mathrm{O}_{2}$ (model) had significantly 


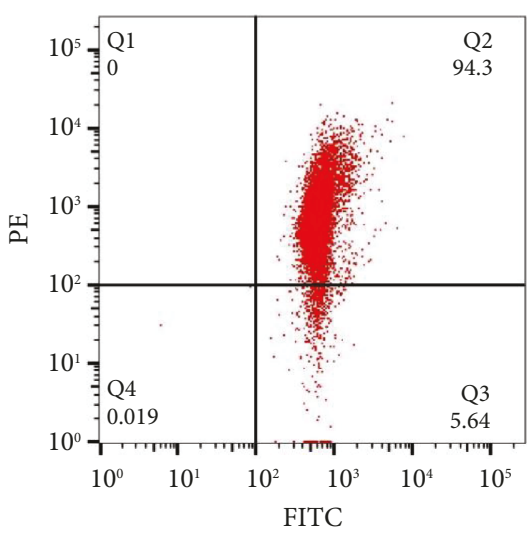

(a)

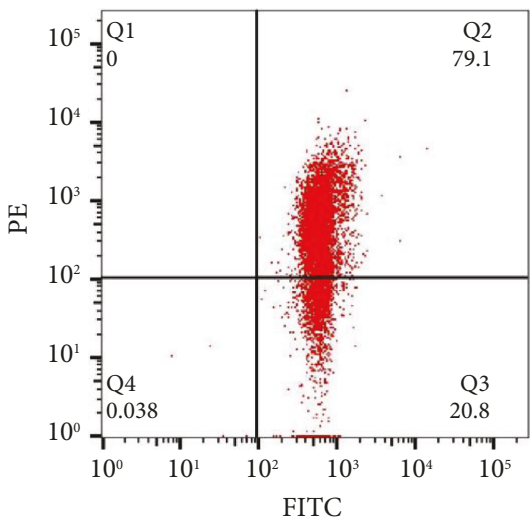

(c)

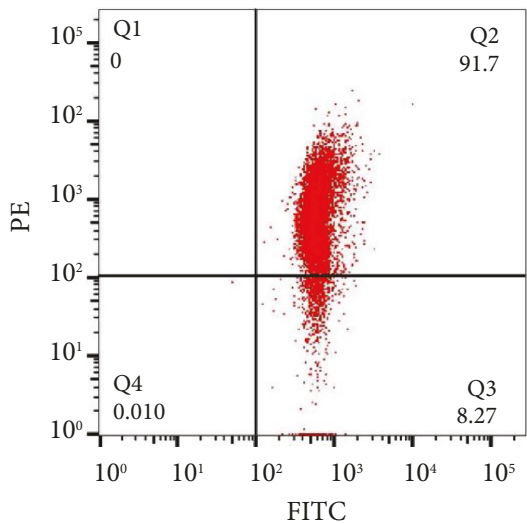

(e)

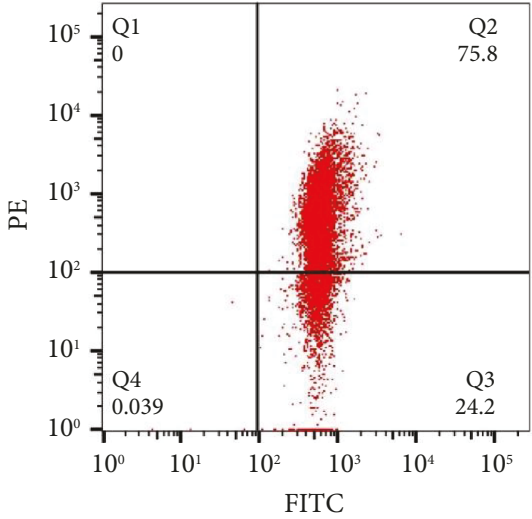

(b)

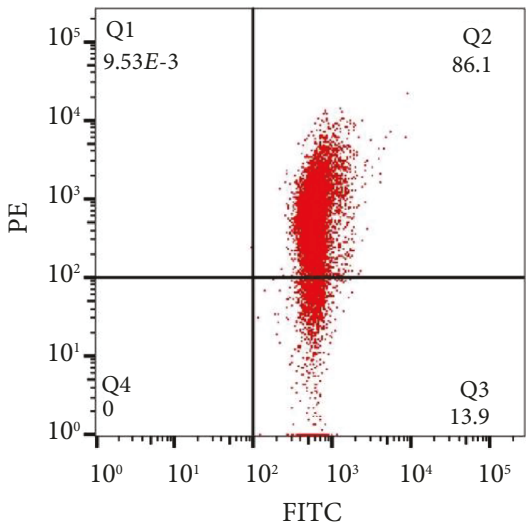

(d)

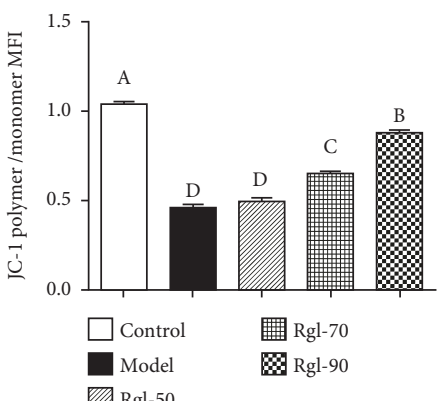

(f)

Figure 4: Effect of $\operatorname{Rg} 1$ on mitochondrial depolarization. Cells $\left(5 \times 10^{6}\right)$ were treated with $\operatorname{Rg} 1(0,50,70$, and $90 \mu \mathrm{g} / \mathrm{mL})$ for $24 \mathrm{~h}$ first and then incubated in media with (model) or without (control) $\mathrm{H}_{2} \mathrm{O}_{2}(100 \mu \mathrm{mol} / \mathrm{L})$ for an additional $4 \mathrm{~h}$. After that, cells $\left(1 \times 10^{5}\right)$ were incubated with JC-1 $(5 \mu \mathrm{g} / \mathrm{mL})$ and assayed by FCM. Mitochondrial depolarization was presented by a reduction in the red/green fluorescence intensity ratio: (a) control group; (b) model group; (c) $50 \mu \mathrm{g} / \mathrm{mL}$ Rg1 group; (d) $70 \mu \mathrm{g} / \mathrm{mL} \mathrm{Rg} 1$ group; (e) $90 \mu \mathrm{g} / \mathrm{mL} \mathrm{Rg} 1$ group; (f) bar diagram representing JC-1 polymer/monomer MFI. All data are presented as mean \pm S.E. $(n=6)$. Bars with different letters were significantly different $(P<0.01)$.

enhanced green fluorescence intensity than the control $(P<0.01)$. Interestingly, treatment with $\operatorname{Rg} 1 \quad(70$ and $90 \mu \mathrm{g} / \mathrm{mL}$ ) significantly reduced green fluorescence intensity when compared to the model $(P<0.01)$.

3.5. Transcriptome Profiling of Gene Expression. The results showed that the average of the clean read rate was
$97.20 \%$, and the average of the mapping rate was $87.24 \%$. The detailed information of each sample is shown in Supplementary Materials: Table S1. The DEGs were represented in Figure 6. A total of 428 genes were identified as DEGs, of which 105 genes were upregulated, while 323 genes were downregulated. The information of DEGs including the gene symbol and gene description was listed in 


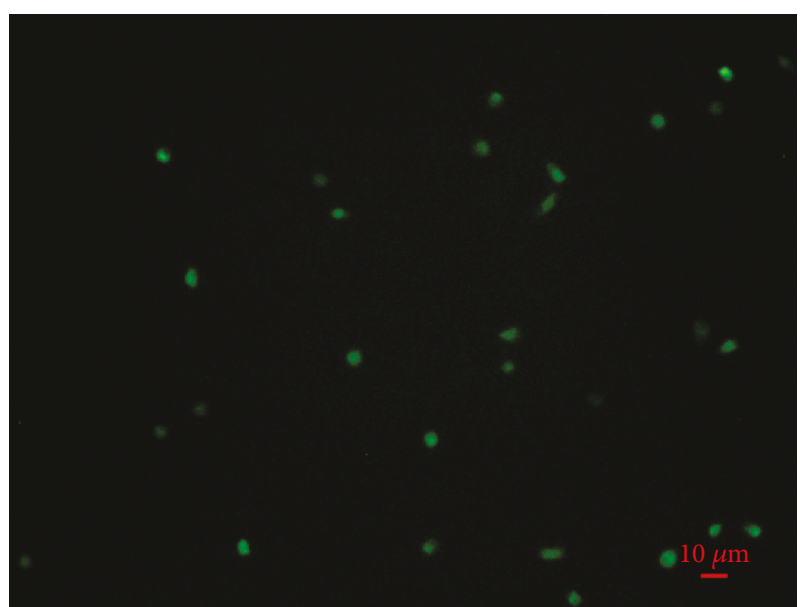

(a)

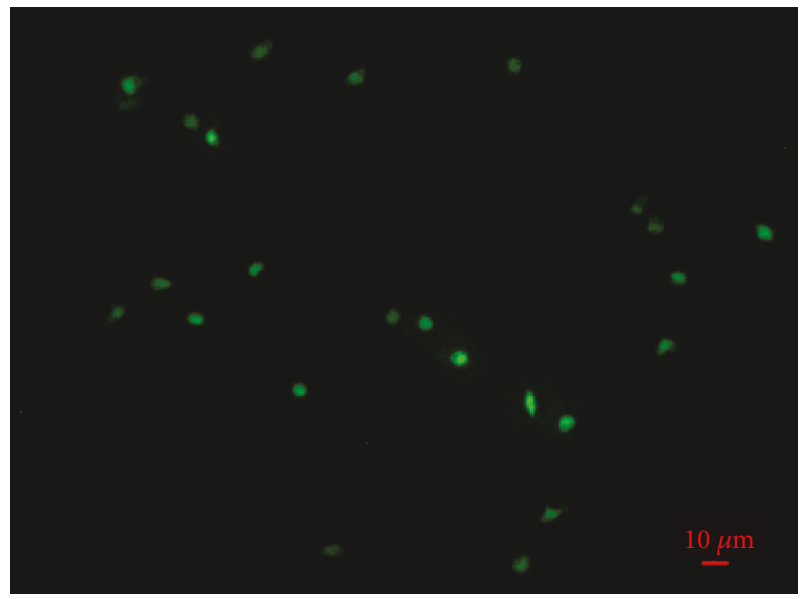

(c)

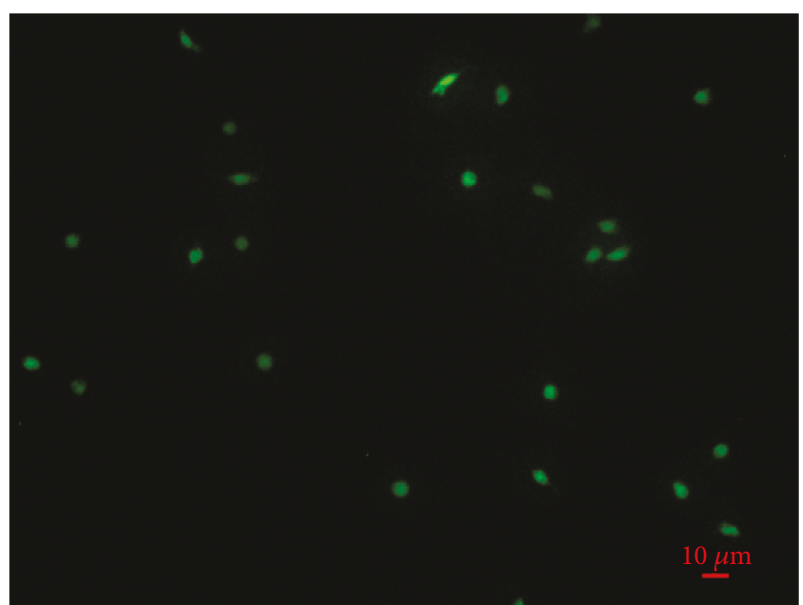

(e)

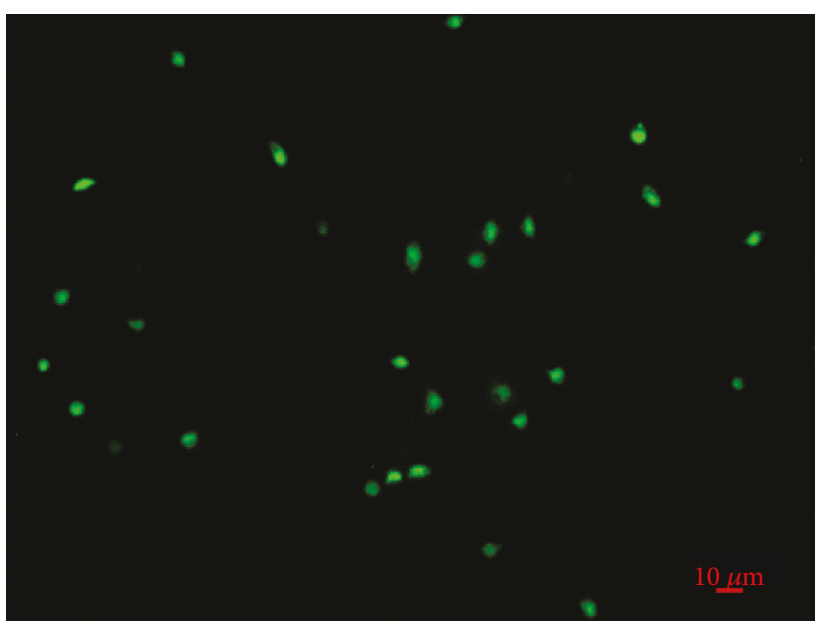

(b)

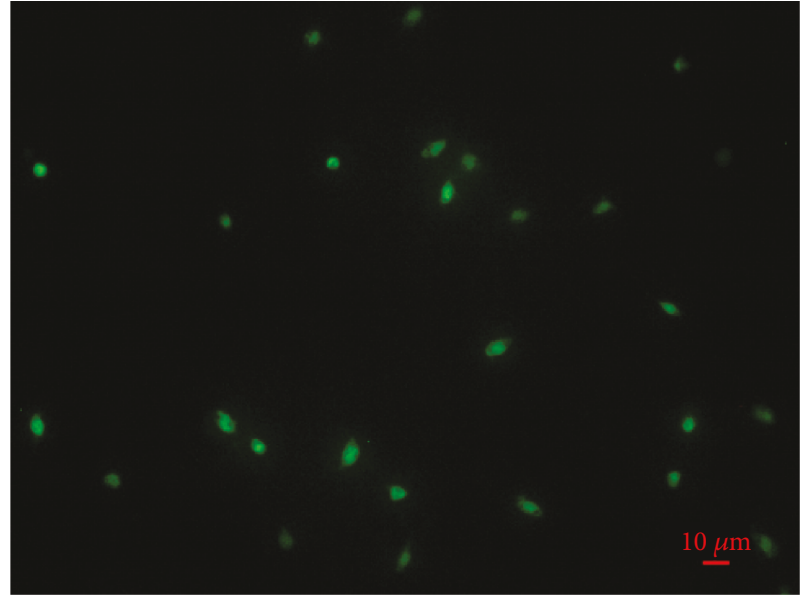

(d)

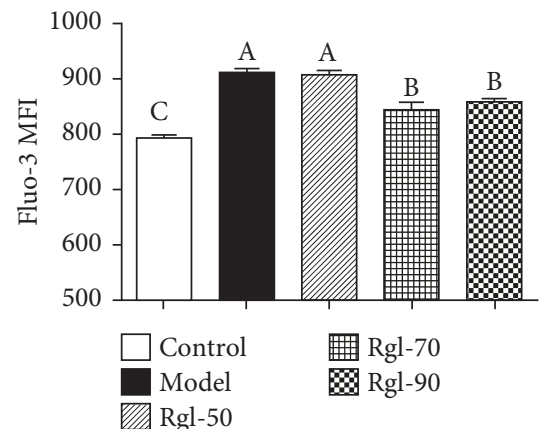

(f)

FIGURE 5: Effects of $\mathrm{Rg} 1$ on $\mathrm{H}_{2} \mathrm{O}_{2}$-induced changes in the $\left[\mathrm{Ca}^{2+}\right] \mathrm{i}$ levels. Cells $\left(5 \times 10^{6}\right)$ were treated with $\mathrm{Rg} 1(0,50,70$, and $90 \mu \mathrm{g} / \mathrm{mL})$ for $24 \mathrm{~h}$ first and then incubated in media with (model) or without (control) $\mathrm{H}_{2} \mathrm{O}_{2}(100 \mu \mathrm{mol} / \mathrm{L}$ ) for an additional $4 \mathrm{~h}$. After incubation with Fluo3/AM ([Ca $\left.{ }^{2+}\right]$ i probe), cells were directly observed under a microscope and Fluo-3/AM fluorescence was measured by FCM: (a) control group; (b) model group; (c) $50 \mu \mathrm{g} / \mathrm{mL} \mathrm{Rg1} \mathrm{group;} \mathrm{(d)} 70 \mu \mathrm{g} / \mathrm{mL} \mathrm{Rg1} \mathrm{group;} \mathrm{(e)} 90 \mu \mathrm{g} / \mathrm{mL}$ Rg1 group; (f) bar diagram representing Fluo-3 MFI. All data are presented as mean \pm S.E. $(n=6)$. Bars with different letters were significantly different $(P<0.05)$. 


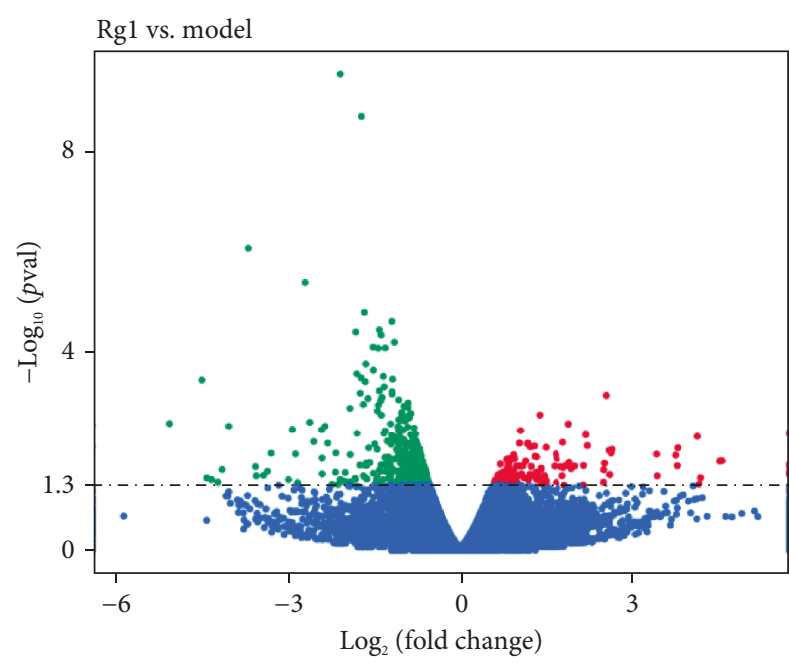

Figure 6: Volcano plot of DEGs in the comparison of Rg1 vs. the model. Red dots indicate differentially expressed genes which are upregulated, green dots indicate differentially expressed genes which are downregulated, and blue dots represent genes with no significant difference.

Supplementary Materials: Table S2. According to the GO classifications, "silicate transport," "regulation of cyclindependent protein," and "regulation of serine/threonine kinase activity" were the predominant terms in the molecular function category. Meanwhile, "purine nucleotide catabolic process," "glutathione metabolic process," and "cAMP catabolic process" were the predominant terms in the biological process category. In addition, we also found "tumor necrosis factor receptor binding" and "tumor necrosis factor receptor superfamily binding" in the biological process category (Figure 7). As shown in Figure 8, we identified ten DEGs in the Toll-like receptor signaling pathway, nine of which were downregulated, whereas one was upregulated. In addition, seven DEGs in the PPAR signaling pathway and twelve DEGs in the cytokinecytokine receptor interaction were downregulated. We also identified eleven DEGs and four DEGs in the mitogenactivated protein kinase (MAPK) signaling pathway and p53 signaling pathway.

3.6. Confirmation of Selected DEG Candidates by RT-qPCR. To validate the RNA-seq results, seventeen DEGs on the transcript level were measured by RT-qPCR. As shown in Figure 9, the tendency of the RT-qPCR results was in accord with the transcriptome sequencing data.

\section{Discussion}

Lymphocytes play important roles in cellular and humoral immune responses in chickens [14]. Because lymphocytes possess many unsaturated fatty acids in their plasma membranes, they are particularly vulnerable to ROS [42]. In the poultry industry, many environmental factors cause overproduction of ROS which may induce oxidative stress, damage the structure of lymphocytes, and suppress the immunity [43]. $\mathrm{H}_{2} \mathrm{O}_{2}$ has been usually experimentally used to stimulate production of ROS in vitro. Similar to the process found in vivo, exogenous $\mathrm{H}_{2} \mathrm{O}_{2}$ traverses the cell membrane; destroys nucleic acid, proteins, and lipid function; wrecks $\left[\mathrm{Ca}^{2+}\right] \mathrm{i}$ homeostasis; and activates mitochondria signals, ultimately leading to cell apoptosis [44-47]. In the present study, exposure of lymphocytes to $\mathrm{H}_{2} \mathrm{O}_{2}$ for $4 \mathrm{~h}$ significantly caused intracellular oxidative stress. During stress, lymphocytes were seriously damaged since the cell viability was significantly decreased. Oxidative stress also causes increased apoptotic lymphocytes as implied by increased Annexin Vpositive and PI-negative cells under stress. The mitochondrial depolarization is considered to be an early stage in an activated apoptotic pathway of mitochondria and often reflected by the increased ratio of JC-1 polymer/monomer fluorescence in cells [28]. In the present study, $\mathrm{H}_{2} \mathrm{O}_{2}$ remarkably decreased mitochondrial membrane potential of lymphocytes, suggesting that mitochondrial apoptosis was activated. $\left[\mathrm{Ca}^{2+}\right] \mathrm{i}$ overload induces apoptosis by releasing proapoptotic factors and breaking the mitochondrial respiratory chain $[48,49] .\left[\mathrm{Ca}^{2+}\right] \mathrm{i}$ concentration is often estimated by intracellular Fluo-3 fluorescent intensity [29]. In this study, $\mathrm{H}_{2} \mathrm{O}_{2}$ significantly increased $\left[\mathrm{Ca}^{2+}\right] \mathrm{i}$ concentration, which further confirmed that cell apoptosis was increased. Due to the damage of lymphocytes under oxidative stress, suppressed immune responses to vaccination in association with oxidative stress were observed in chickens in our previous study [19].

The present study demonstrated that $\mathrm{Rg} 1$ has protective effect on $\mathrm{H}_{2} \mathrm{O}_{2}$-induced damage of chicken lymphocytes as evidenced by increased cell viability and reversed redox status. Antioxidant effect of plant extracts in chicken lymphocytes has been reported in other studies. Zhang et al. observed that Sargassum polysaccharide inhibited oxidative stress induced by infectious bursa disease virus in bursal lymphocytes of chickens [50]. Lv et al. found that a polysaccharide from Agaricus blazei Murill had antioxidant effect in chicken peripheral blood lymphocytes treated with cadmium [51]. In this study, $\operatorname{Rg} 1$ significantly reduced oxidative stressinduced apoptosis and damage of chicken lymphocytes. Rg1reduced apoptosis of lymphocytes in chickens may be related to recovered mitochondrial membrane potential, as found in mammals $[52,53]$. The in vitro findings in this study may explain the protective effect of $\mathrm{Rg} 1$ on the immune response against oxidative stress in chickens in previously found in vivo studies [9].

With the chicken genome project completed, genomewide gene expression analysis has been used in poultry research $[54,55]$. In the present study, we used RNA-seq technology to detect gene expressions across the entire chicken genome to provide predictable pathways in the comparison of Rg1 vs. the model. Since Rg1 at $90 \mu \mathrm{g} / \mathrm{mL}$ provides optimal protective effect on cells, treatment of lymphocytes with $\mathrm{Rg} 1$ at this dose was used to identify genes that were differentially expressed between Rg1-treated and the model. About $25.5 \%$ of DEGs were upregulated and $75.5 \%$ of DEGs were downregulated. Interestingly, these DEGs were involved in GO terms related to apoptosis such as regulation of serinethreonine protein kinases, tumor necrosis factor receptor binding, and tumor necrosis factor receptor superfamily 


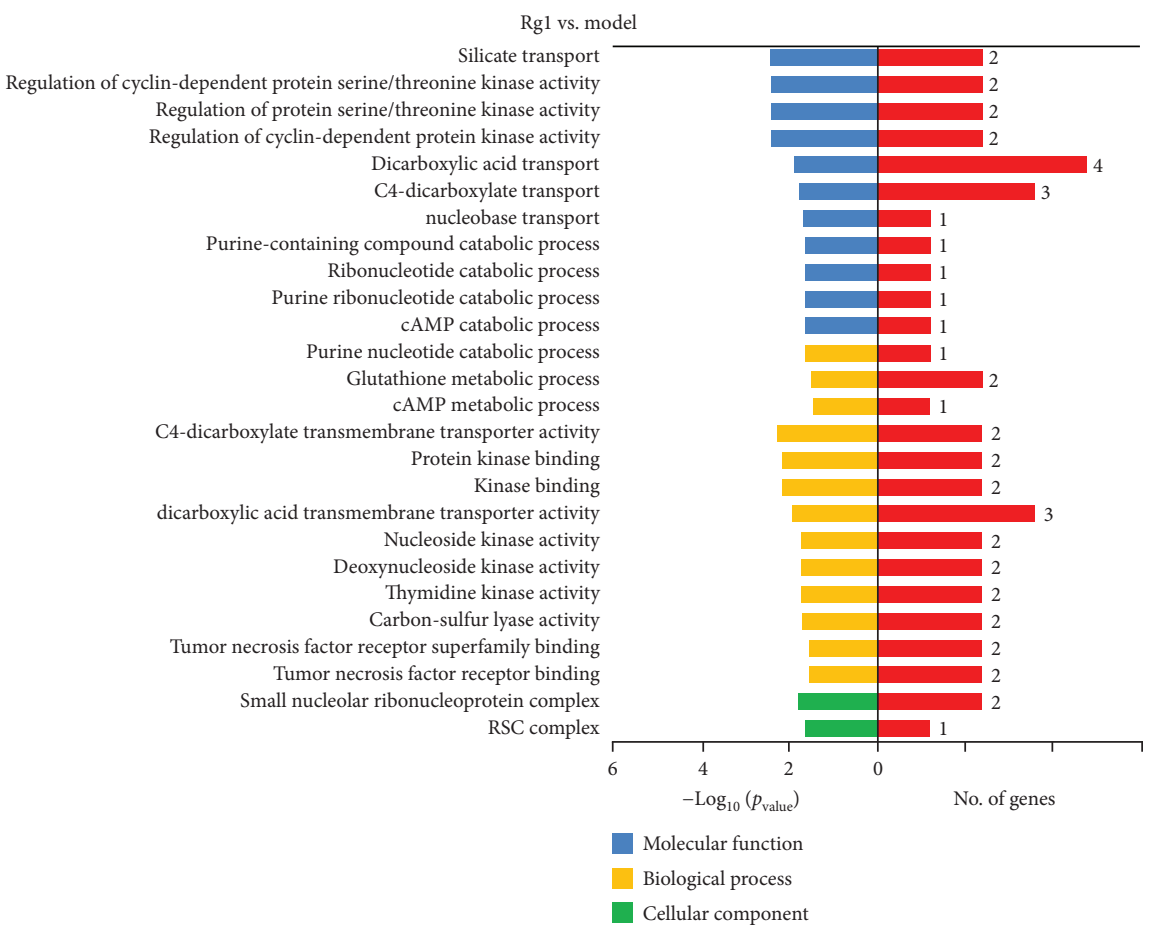

Figure 7: GO functional enrichment analysis. The DEGs between the Rg1 and model groups were classified based on Gene Ontology.

Rg1 vs. model

Toll-like receptor signaling pathway

PPAR signaling pathway

Cytokine-cytokine receptor interaction

MAPK signaling pathway

NOD-like receptor signaling pathway

Protein processing in endoplasmic reticulum

RIG-I-like receptor signaling pathway

Phenylalanine metabolism

p53 signaling pathway

Focal adhesion

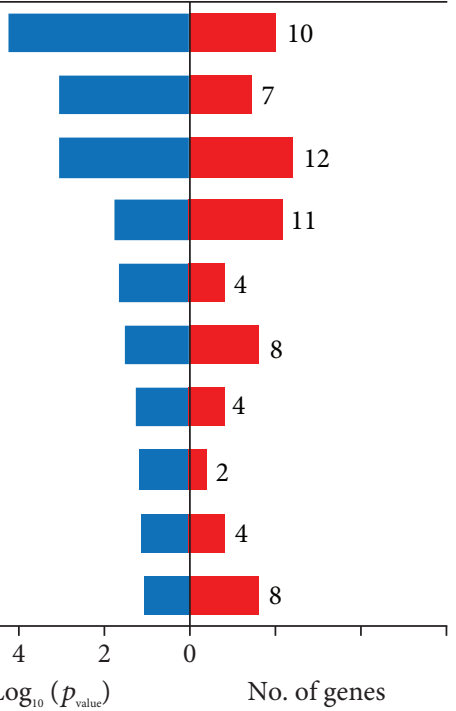

FIGURE 8: KEGG pathway analysis. The enriched pathways among the DEGs were identified by KEGG analysis.

binding. In line with the GO enrichment analysis, KEGG pathway analysis revealed that DEGs were involved in the Toll-like receptor signaling pathway, PPAR signaling pathway, MAPK signaling pathway, and p53 signaling pathway, which were associated with regulation of apoptosis.

Tumor necrosis factor alpha (TNF- $\alpha$ ) has a far wider range than the original described antitumor activity and is one of the most important cytokines in mediating inflammatory and immune responses [56, 57]. The production of TNF- $\alpha$ and subsequent binding by TNF receptors trigger a cascade of intracellular processes with diverse effects such as apoptosis in mammals and birds $[58,59]$. In the present study, RELT, TNFRSF8, TNFRSF6B, and EDA2R, which are representatives involved in cytokine-cytokine receptor interaction, were downregulated by $\mathrm{Rg} 1$. As a member of the TNF receptor superfamily, RELT is able to bind tumor necrosis factor receptor-associated factor 1 and induce cell apoptosis [60-62]. TNFRSF6, which is a well-known member in TNFRSF, combines with Fas ligand TNFSF6 to induce apoptotic cell death in cells that express this receptor molecule [56]. The downregulated genes related to cytokinecytokine receptor interaction indicated their potential role 


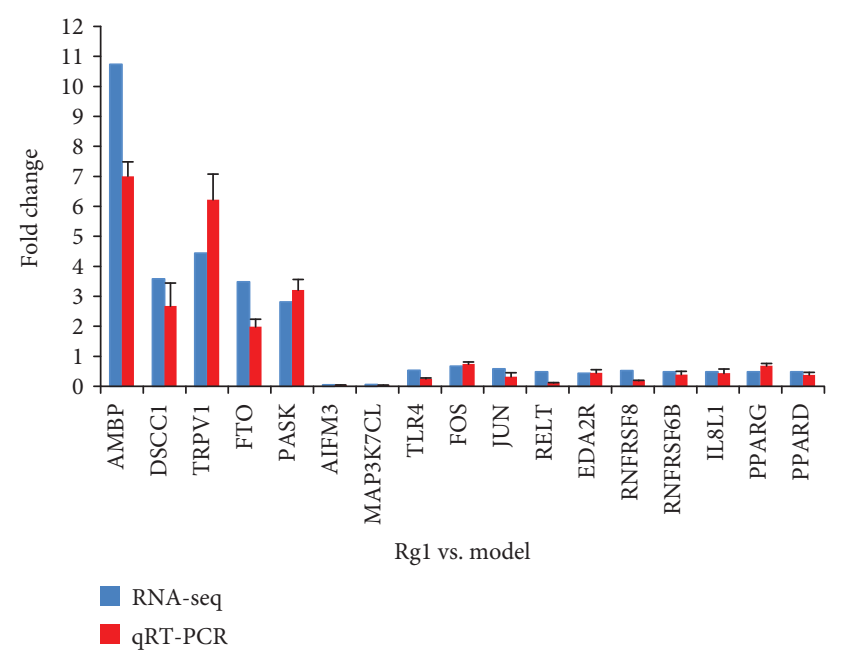

FIGURE 9: Gene expression determined by RNA-seq and RT-qPCR $(n=3)$. RT-qPCR validation of seventeen differentially expressed genes in the comparison of $\operatorname{Rg} 1$ vs. the model. The data were normalized to the expression of $\beta$-actin, and the fold changes were calculated as Rg1/model.

in reducing apoptotic lymphocytes by $\mathrm{Rg} 1$ and were worth of further investigation. Su et al. have observed that $\mathrm{Rg} 1$ decreased TNF- $\alpha$ production in activated mice macrophage [24]. Consistently, we showed that Rg1 inhibited gene expression of TNF receptors in oxidative-stressed chicken lymphocytes. Other plant extracts such as Agaricus blazei Murill polysaccharides were reported to protect against oxidative stress and reduce expression of TNF- $\alpha$ in the spleen of chickens, which was similar to our results [63]. Because the genes of the TNF receptor family were decreased in the Rg1 group, it seems that Rg1 protected lymphocytes of oxidative stress by inhibiting production of cytokines related to cell apoptosis.

Toll-like receptors (TLRs) are membrane-bound receptors and play crucial roles in innate immunity by recognizing pathogen-associated molecular patterns and inducing downstream signaling pathways that activate innate immune responses and produce inflammatory cytokines [64-66]. However, TLRs also play an important role in TNF- $\alpha$ induced apoptosis $[67,68]$. In this study, nine genes involved in the Toll-like receptor signaling pathway were significantly decreased by Rg1, such as TLR4, FOS, JUN, and MAP2K3. TLR4 is one of the important members of TLRs, and it also recognizes plant-derived molecules such as taxol and ginsenosides $[69,70]$. It was demonstrated that ginsenoside Rg1 could enhance immune responses via the TLR4 signaling pathway [71]. However, another study reported that Rg1 could decrease the inflammation factors by inhibiting TLR3 and TLR4 signaling pathways [72]. Other plant extracts such as Astragalus polysaccharide also displayed regulating effect on TLR4 expression in chickens [73]. In view of these results, it is likely that $\mathrm{Rg} 1$ suppressed expression of apoptosisrelated genes through suppression of TLR4. As inducible transcription factors, the protooncogenes c-FOS and c-JUN can be translated to FOS and JUN, which can compose a heterodimeric complex that interacts with the activator protein-
1 (AP-1) binding site and function cooperatively in signal transduction processes [74]. Interestingly, accumulated evidences have implicated that AP-1 transcription factor complexes can positively or negatively modulate distinct apoptotic pathways, depending on the different microenvironments and cell types $[75,76]$. Considering that the expression of FOS and JUN was markedly decreased in the Rg1 group, we speculated that downregulated expression of apoptosis-related genes in oxidative-stressed lymphocytes by $\mathrm{Rg} 1$ was associated with decreased AP-1.

In addition to the cytokine-cytokine receptor interaction and the Toll-like receptor signaling pathway, we also identified seven downregulated DEGs involved in the PPAR signaling pathway. Nevertheless, ten DEGs were decreased, and one DEG was increased involved in the MAPK signaling pathway by $\operatorname{Rg} 1$. A previous study showed that PPAR $\gamma$, which is a member of PPARs, played an important role in apoptosis of the chicken pancreas [77]. MAPK is a family of serine-threonine protein kinases that is activated in response to various extracellular stimuli and plays key roles in the biological process such as cell apoptosis and cytokine production in chickens [58, 78]. We also identified four DEGs involved in the p53 signaling pathway in the comparison of Rg1 vs. the model. Considering the important role of PPARs, MAPK, and p53 during apoptosis in birds, we speculated that Rg1 might reduce apoptosis of chicken lymphocytes via multiple mechanisms [79].

The present study demonstrated that Rg1 significantly inhibited production of ROS and MDA, decreased apoptosis, and enhanced viability in lymphocytes. The antioxidant property of Rg1 may explain its immune-potentiating effect on birds with oxidative stress as found in our previous study [9]. Numerous DEGs between Rg1-treated and model lymphocytes were identified. Of them, 323 genes were downregulated and 105 genes were upregulated in Rg1-treated cells. The DEGs were involved in Toll-like receptors, PPAR signaling pathway, and cytokine-cytokine receptor interaction. The present study indicated that Rg1 may act as an antioxidative agent to protect cell damage caused by oxidative stress via regulation of gene expression.

\section{Data Availability}

The data used to support the findings of this study are available from the corresponding author upon request.

\section{Conflicts of Interest}

The authors declare that they have no competing interests.

\section{Authors' Contributions}

Shicheng Bi and Songhua $\mathrm{Hu}$ conceived and designed the experiments. Shicheng Bi, Xiaodan $\mathrm{Ma}$, and Yuemin Wang performed the experiments. Shicheng Bi, Wei Xu, and Yong Zhang analyzed the data. Xiaoqing Chi and Yong Zhang contributed reagents and materials. Shicheng $\mathrm{Bi}$ and Songhua $\mathrm{Hu}$ wrote the paper. 


\section{Acknowledgments}

The authors are grateful to the students in the Laboratory of Traditional Chinese Veterinary Medicine (TCVM Lab) for their assistance in the present study. This study was supported by the project (No. 31172356) of the National Natural Science Foundation of China and the Special Fund for Agroscientific Research in the Public Interest of China.

\section{Supplementary Materials}

Table S1: summary of the sequencing and the read mapping of the model and Rg1 groups. Table S2: list of the up-/downregulated DEGs in comparison of Rg1 vs. the model. Table S3: sequences of primers for RT-qPCR. (Supplementary Materials)

\section{References}

[1] A. K. Panda and G. Cherian, "Role of vitamin E in counteracting oxidative stress in poultry," The Journal of Poultry Science, vol. 51, no. 2, pp. 109-117, 2014.

[2] K. Mani, K. Sundaresan, and K. Viswanathan, "Effect of aflatoxin B1 on immunity to Newcastle disease in commercial broilers," Indian Veterinary Journal, vol. 77, no. 3, pp. 193195, 2000.

[3] S. Yuan, B. Wu, Z. Yu et al., "The mitochondrial and endoplasmic reticulum pathways involved in the apoptosis of bursa of Fabricius cells in broilers exposed to dietary aflatoxin B1," Oncotarget, vol. 7, no. 40, pp. 65295-65306, 2016.

[4] J. Chen, K. Chen, S. Yuan et al., "Effects of aflatoxin $B_{1}$ on oxidative stress markers and apoptosis of spleens in broilers," Toxicology and Industrial Health, vol. 32, no. 2, pp. 278-284, 2016.

[5] M. Chen, X. Li, R. Fan et al., "Cadmium induces BNIP3dependent autophagy in chicken spleen by modulating miR33-AMPK axis," Chemosphere, vol. 194, pp. 396-402, 2018.

[6] W. Wang, M. Chen, X. Jin et al., " $\mathrm{H}_{2} \mathrm{~S}$ induces Th1/Th2 imbalance with triggered NF- $\kappa \mathrm{B}$ pathway to exacerbate LPS-induce chicken pneumonia response," Chemosphere, vol. 208, pp. 241-246, 2018.

[7] J. Aurelius, Mechanisms of Leukemia-Induced Immunosuppression, University of Gothenburg, 2012.

[8] X. He, F. Qu, F. Zhou et al., "High leukocyte mtDNA content contributes to poor prognosis through ROS-mediated immunosuppression in hepatocellular carcinoma patients," Oncotarget, vol. 7, no. 16, pp. 22834-22845, 2016.

[9] D. Xu, W. Li, Y. Huang, J. He, and Y. Tian, "The effect of selenium and polysaccharide of Atractylodes macrocephala Koidz. (PAMK) on immune response in chicken spleen under heat stress," Biological Trace Element Research, vol. 160, no. 2, pp. 232-237, 2014.

[10] C. Liu, M. Li, Y. Cao et al., "Effects of avermectin on immune function and oxidative stress in the pigeon spleen," ChemicoBiological Interactions, vol. 210, pp. 43-50, 2014.

[11] X. Luo, S. Jia, Q. Ma et al., "Suppressive effects of subchronic aluminum overload on the splenic immune function may be related to oxidative stress in mice," Biological Trace Element Research, vol. 157, no. 3, pp. 249-255, 2014.

[12] J. Yu, Y. Chen, L. Zhai et al., "Antioxidative effect of ginseng stem-leaf saponins on oxidative stress induced by cyclophosphamide in chickens," Poultry Science, vol. 94, no. 5, pp. 927-933, 2015.

[13] J. Sun, S. Hu, and X. Song, “Adjuvant effects of protopanaxadiol and protopanaxatriol saponins from ginseng roots on the immune responses to ovalbumin in mice," Vaccine, vol. 25, no. 6, pp. 1114-1120, 2007.

[14] L. Zhai, Y. Li, W. Wang, Y. Wang, and S. Hu, "Effect of oral administration of ginseng stem-and-leaf saponins (GSLS) on the immune responses to Newcastle disease vaccine in chickens," Vaccine, vol. 29, no. 31, pp. 5007-5014, 2011.

[15] M. Korivi, C. W. Hou, C. Y. Huang et al., “Ginsenoside-Rg1 protects the liver against exhaustive exercise-induced oxidative stress in rats," Evidence-based Complementary and Alternative Medicine, vol. 2012, Article ID 932165, 8 pages, 2012.

[16] S. H. Yu, H. Y. Huang, M. Korivi et al., "Oral Rg1 supplementation strengthens antioxidant defense system against exerciseinduced oxidative stress in rat skeletal muscles," Journal of the International Society of Sports Nutrition, vol. 9, no. 1, p. 23, 2012.

[17] D. Zhu, L. Wu, C. R. Li et al., "Ginsenoside Rg1 protects rat cardiomyocyte from hypoxia/reoxygenation oxidative injury via antioxidant and intracellular calcium homeostasis," Journal of Cellular Biochemistry, vol. 108, no. 1, pp. 117-124, 2009.

[18] Y. Liu, L. Yi, L. Wang, L. Chen, X. Chen, and Y. Wang, "Ginsenoside Rg1 protects human umbilical cord blood-derived stromal cells against tert-butyl hydroperoxide-induced apoptosis through Akt-FoxO3a-Bim signaling pathway," Molecular and Cellular Biochemistry, vol. 421, no. 1-2, pp. 75-87, 2016.

[19] S. Bi, X. Chi, Y. Zhang et al., "Ginsenoside Rg1 enhanced immune responses to infectious bursal disease vaccine in chickens with oxidative stress induced by cyclophosphamide," Poultry Science, vol. 97, no. 8, pp. 2698-2707, 2018.

[20] J. Huo, Z. Xu, K. Hosoe et al., "Coenzyme Q10 prevents senescence and dysfunction caused by oxidative stress in vascular endothelial cells," Oxidative Medicine and Cellular Longevity, vol. 2018, Article ID 3181759, 15 pages, 2018.

[21] X. Lin, S. Jiang, Z. Jiang, C. Zheng, and Z. Gou, "Effects of equol on $\mathrm{H} 2 \mathrm{O} 2$-induced oxidative stress in primary chicken intestinal epithelial cells," Poultry Science, vol. 95, no. 6, pp. 1380-1386, 2016.

[22] S. Liu, F. P. Xu, Z. J. Yang, M. Li, Y. H. Min, and S. Li, "Cadmium-induced injury and the ameliorative effects of selenium on chicken splenic lymphocytes: mechanisms of oxidative stress and apoptosis," Biological Trace Element Research, vol. 160, no. 3, pp. 340-351, 2014.

[23] N. Pathak and S. Khandelwal, "Oxidative stress and apoptotic changes in murine splenocytes exposed to cadmium," Toxicology, vol. 220, no. 1, pp. 26-36, 2006.

[24] F. Su, Y. Xue, Y. Wang, L. Zhang, W. Chen, and S. Hu, "Protective effect of ginsenosides Rg1 and Re on lipopolysaccharideinduced sepsis by competitive binding to Toll-like receptor 4," Antimicrobial Agents and Chemotherapy, vol. 59, no. 9, pp. 5654-5663, 2015.

[25] W. J. Li, L. Li, W. Y. Zhen et al., "Ganoderma atrum polysaccharide ameliorates ROS generation and apoptosis in spleen and thymus of immunosuppressed mice," Food and Chemical Toxicology, vol. 99, pp. 199-208, 2017.

[26] R. Li, K. Sakwiwatkul, L. Yutao, and S. Hu, "Enhancement of the immune responses to vaccination against foot-andmouth disease in mice by oral administration of an extract 
made from Rhizoma Atractylodis Macrocephalae (RAM)," Vaccine, vol. 27, no. 15, pp. 2094-2098, 2009.

[27] Z. Li, W. Pan, Y. Shen et al., "IGF1/IGF1R and microRNA let7e down-regulate each other and modulate proliferation and migration of colorectal cancer cells," Cell Cycle, vol. 17, no. 10, pp. 1212-1219, 2018.

[28] X. Peng, Z. Yu, N. Liang et al., "The mitochondrial and death receptor pathways involved in the thymocytes apoptosis induced by aflatoxin $\mathrm{B}_{1}$," Oncotarget, vol. 7 , no. 11, pp. 12222-12234, 2016.

[29] W. Xu, R. Guan, F. Shi, A. du, and S. Hu, "Structural analysis and immunomodulatory effect of polysaccharide from Atractylodis macrocephalae Koidz. on bovine lymphocytes," Carbohydrate Polymers, vol. 174, pp. 1213-1223, 2017.

[30] X. Cui, Y. Hou, S. Yang et al., "Transcriptional profiling of mammary gland in Holstein cows with extremely different milk protein and fat percentage using RNA sequencing," BMC Genomics, vol. 15, no. 1, p. 226, 2014.

[31] Z. Zhuo, S. Fang, Q. Hu, D. Huang, and J. Feng, "Digital gene expression profiling analysis of duodenum transcriptomes in SD rats administered ferrous sulfate or ferrous glycine chelate by gavage," Scientific Reports, vol. 6, no. 1, article 37923, 2016.

[32] J. Zhang, Y. Geng, F. Guo et al., "Screening and identification of critical transcription factors involved in the protection of cardiomyocytes against hydrogen peroxide-induced damage by Yixin-shu," Scientific Reports, vol. 7, no. 1, article 13867, 2017.

[33] R. Liang, B. Han, Q. Li, Y. Yuan, J. Li, and D. Sun, "Using RNA sequencing to identify putative competing endogenous RNAs (ceRNAs) potentially regulating fat metabolism in bovine liver," Scientific Reports, vol. 7, no. 1, article 6396, 2017.

[34] F. Yang, H. Cao, Q. Xiao et al., "Transcriptome analysis and gene identification in the pulmonary artery of broilers with ascites syndrome," PLoS One, vol. 11, no. 6, article e0156045, 2016.

[35] W. Xu, A. du, and S. Hu, "Transcriptome analysis of bovine lymphocytes stimulated by Atractylodis macrocephalae Koidz. polysaccharides in vitro," Veterinary Immunology and Immunopathology, vol. 196, pp. 30-34, 2018.

[36] G. Li, X. J. Wu, X. Q. Kong, L. Wang, and X. Jin, “Cytochrome c oxidase subunit VIIb as a potential target in familial hypercholesterolemia by bioinformatical analysis," European Review for Medical and Pharmacological Sciences, vol. 19, no. 21, pp. 4139-4145, 2015.

[37] S. T. Zhang, C. Zuo, W. N. Li, X. Q. Fu, S. Xing, and X. P. Zhang, "Identification of key genes associated with the effect of estrogen on ovarian cancer using microarray analysis," Archives of Gynecology and Obstetrics, vol. 293, no. 2, pp. 421-427, 2016.

[38] J. Gao, Y. Li, T. Wang et al., "Analyzing gene expression profiles with preliminary validations in cardiac hypertrophy induced by pressure overload," Canadian Journal of Physiology and Pharmacology, vol. 96, no. 8, pp. 701-709, 2018.

[39] C. Wan, J. Xiang, Y. Li, and D. Guo, "Differential gene expression patterns in chicken cardiomyocytes during hydrogen peroxide-induced apoptosis," PLoS One, vol. 11, no. 1, article e0147950, 2016.

[40] X. Cui, B. Marshall, N. Shi, S.-Y. Chen, R. Rekaya, and H.-X. Liu, "RNA-Seq analysis on chicken taste sensory organs: an ideal system to study organogenesis," Scientific Reports, vol. 7, no. 1, article 9131, 2017.
[41] R. Han, X. Wang, D. Wang et al., "GPR143 gene mutations in five Chinese families with X-linked congenital nystagmus," Scientific Reports, vol. 5, no. 1, p. 12031, 2015.

[42] S. N. Meydani, D. Wu, M. S. Santos, and M. G. Hayek, “Antioxidants and immune response in aged persons: overview of present evidence," American Journal of Clinical Nutrition, vol. 62, no. 6, pp. 1462S-1476S, 1995.

[43] J. A. Knight, "Review: free radicals, antioxidants, and the immune system," Annals of Clinical \& Laboratory Science, vol. 30, no. 2, pp. 145-158, 2000.

[44] C. Shi, F. Wu, and J. $\mathrm{Xu},{ }^{~} \mathrm{H}_{2} \mathrm{O}_{2}$ and PAF mediate $\mathrm{A} \beta 1-42-$ induced $\mathrm{Ca}^{2+}$ dyshomeostasis that is blocked by EGb761," Neurochemistry International, vol. 56, no. 8, pp. 893-905, 2010.

[45] J. A. Rosado, A. M. Nuñez, J. J. Lopez, J. A. Pariente, and G. M. Salido, "Intracellular $\mathrm{Ca}^{2+}$ homeostasis and aggregation in platelets are impaired by ethanol through the generation of $\mathrm{H}_{2} \mathrm{O}_{2}$ and oxidation of sulphydryl groups," Archives of Biochemistry and Biophysics, vol. 452, no. 1, pp. 9-16, 2006.

[46] X. Fan, R. Hussien, and G. A. Brooks, "H2O2-induced mitochondrial fragmentation in $\mathrm{C} 2 \mathrm{C} 12$ myocytes," Free Radical Biology \& Medicine, vol. 49, no. 11, pp. 1646-1654, 2010.

[47] M. E. Tome, K. Lee, M. C. Jaramillo, and M. M. Briehl, "Mitochondria are the primary source of the $\mathrm{H} 2 \mathrm{O} 2$ signal for glucocorticoid-induced apoptosis of lymphoma cells," Experimental and Therapeutic Medicine, vol. 4, no. 2, pp. 237-242, 2012.

[48] X. Chen, X. Zhang, H. Kubo et al., "Ca2+ influx-induced sarcoplasmic reticulum $\mathrm{Ca} 2+$ overload causes mitochondrialdependent apoptosis in ventricular myocytes," Circulation Research, vol. 97, no. 10, pp. 1009-1017, 2005.

[49] L. Wei, N. Lu, Q. Dai et al., "Different apoptotic effects of wogonin via induction of $\mathrm{H}_{2} \mathrm{O}_{2}$ generation and $\mathrm{Ca}^{2+}$ overload in malignant hepatoma and normal hepatic cells," Journal of Cellular Biochemistry, vol. 111, no. 6, pp. 16291641, 2010.

[50] L. Zhang, T. J. Hu, H. L. Liu, and X. H. Shuai, "Inhibitory effect of Sargassum polysaccharide on oxidative stress induced by infectious bursa disease virus in chicken bursal lymphocytes," International Journal of Biological Macromolecules, vol. 49, no. 4, pp. 607-615, 2011.

[51] A. Lv, M. Ge, X. Hu, W. Liu, G. Li, and R. Zhang, "Effects of Agaricus blazei Murill polysaccharide on cadmium poisoning on the MDA5 signaling pathway and antioxidant function of chicken peripheral blood lymphocytes," Biological Trace Element Research, vol. 181, no. 1, pp. 122-132, 2018.

[52] C. Zhu, Y. Wang, H. Liu et al., "Oral administration of ginsenoside Rg1 prevents cardiac toxicity induced by doxorubicin in mice through anti-apoptosis," Oncotarget, vol. 8, no. 48, pp. 83792-83801, 2017.

[53] T. Huang, F. Fang, L. Chen et al., "Ginsenoside Rg1 attenuates oligomeric A $\beta 1$-42-induced mitochondrial dysfunction," Current Alzheimer Research, vol. 9, no. 3, pp. 388-395, 2012.

[54] D. J. Coble, D. Fleming, M. E. Persia et al., "RNA-seq analysis of broiler liver transcriptome reveals novel responses to high ambient temperature," BMC Genomics, vol. 15, no. 1, p. 1084, 2014.

[55] A. D. Truong, Y. H. Hong, and H. S. Lillehoj, "RNA-seq profiles of immune related genes in the spleen of necrotic enteritis-afflicted chicken lines," Asian-Australasian Journal of Animal Sciences, vol. 28, no. 10, pp. 1496-1511, 2015. 
[56] M. F. Mcdermott, "TNF and TNFR biology in health and disease," Cellular and Molecular Biology (Noisy-le-Grand, France), vol. 47, no. 4, pp. 619-635, 2001.

[57] Y. Hong, H. Lillehoj, S. Hyenlee, D. Woonpark, and E. Lillehoj, "Molecular cloning and characterization of chicken lipopolysaccharide-induced TNF- $\alpha$ factor (LITAF)," Developmental \& Comparative Immunology, vol. 30, no. 10, pp. 919929, 2006.

[58] Z. Xing, C. J. Cardona, J. Anunciacion, S. Adams, and N. Dao, "Roles of the ERK MAPK in the regulation of proinflammatory and apoptotic responses in chicken macrophages infected with H9N2 avian influenza virus," Journal of General Virology, vol. 91, no. 2, pp. 343-351, 2010.

[59] S. R. Wiley, K. Schooley, P. J. Smolak et al., "Identification and characterization of a new member of the TNF family that induces apoptosis," Immunity, vol. 3, no. 6, pp. 673-682, 1995.

[60] T. C. Polek, M. Talpaz, and T. Spivak-Kroizman, “The TNF receptor, RELT, binds SPAK and uses it to mediate p38 and JNK activation," Biochemical and Biophysical Research Communications, vol. 343, no. 1, pp. 125-134, 2006.

[61] G. L. Sica, G. Zhu, K. Tamada, D. Liu, J. Ni, and L. Chen, "RELT, a new member of the tumor necrosis factor receptor superfamily, is selectively expressed in hematopoietic tissues and activates transcription factor NF-kappaB," Blood, vol. 97, no. 9, pp. 2702-2707, 2001.

[62] P. Moua, M. Checketts, L. G. Xu, H. B. Shu, M. E. Reyland, and J. K. Cusick, "RELT family members activate p38 and induce apoptosis by a mechanism distinct from TNFR1," Biochemical and Biophysical Research Communications, vol. 491, no. 1, pp. 25-32, 2017.

[63] W. Xie, A. Lv, R. Li et al., “Agaricus blazei Murill polysaccharides protect against cadmium-induced oxidative stress and inflammatory damage in chicken spleens," Biological Trace Element Research, vol. 184, no. 1, pp. 247-258, 2018.

[64] T. Kawasaki and T. Kawai, "Toll-like receptor signaling pathways," Frontiers in Immunology, vol. 5, p. 461, 2014.

[65] N. D. Temperley, S. Berlin, I. R. Paton, D. K. Griffin, and D. W. Burt, "Evolution of the chicken Toll-like receptor gene family: a story of gene gain and gene loss," BMC Genomics, vol. 9, no. 1, p. 62, 2008.

[66] R. Brownlie and B. Allan, "Avian toll-like receptors," Cell and Tissue Research, vol. 343, no. 1, pp. 121-130, 2011.

[67] J. Yang, X. Guo, J. Yang et al., "RP105 protects against apoptosis in ischemia/reperfusion-induced myocardial damage in rats by suppressing TLR4-mediated signaling pathways," Cellular Physiology and Biochemistry, vol. 36, no. 6, pp. 21372148, 2015.

[68] S. Mukherjee and T. Biswas, "Activation of TOLLIP by porin prevents TLR2-associated IFN- $\gamma$ and TNF- $\alpha$-induced apoptosis of intestinal epithelial cells," Cellular Signalling, vol. 26, no. 12, pp. 2674-2682, 2014.

[69] K. Kawasaki, S. Akashi, R. Shimazu, T. Yoshida, K. Miyake, and M. Nishijima, "Mouse toll-like receptor 4.MD-2 complex mediates lipopolysaccharide-mimetic signal transduction by Taxol," Journal of Biological Chemistry, vol. 275, no. 4, pp. 2251-2254, 2000.

[70] I. A. Lee, S. R. Hyam, S. E. Jang, M. J. Han, and D. H. Kim, "Ginsenoside re ameliorates inflammation by inhibiting the binding of lipopolysaccharide to TLR4 on macrophages," Journal of Agricultural and Food Chemistry, vol. 60, no. 38, pp. 9595-9602, 2012.
[71] F. Su, L. Yuan, L. Zhang, and S. Hu, "Ginsenosides Rg1 and Re act as adjuvant via TLR4 signaling pathway," Vaccine, vol. 30, no. 27, pp. 4106-4112, 2012.

[72] B. S. Zhao, Y. Liu, X. Y. Gao, H. Q. Zhai, J. Y. Guo, and X. Y. Wang, "Effects of ginsenoside Rg1 on the expression of tolllike receptor 3, 4 and their signalling transduction factors in the NG108-15 murine neuroglial cell line," Molecules, vol. 19, no. 10, pp. 16925-16936, 2014.

[73] L. Liu, J. Shen, C. Zhao et al., "Dietary Astragalus polysaccharide alleviated immunological stress in broilers exposed to lipopolysaccharide," International Journal of Biological Macromolecules, vol. 72, pp. 624-632, 2015.

[74] C. Abate, L. Patel, F. Rauscher, and T. Curran, "Redox regulation of fos and jun DNA-binding activity in vitro," Science, vol. 249, no. 4973, pp. 1157-1161, 1990.

[75] D. A. Liebermann, B. Gregory, and B. Hoffman, "AP-1 (Fos/Jun) transcription factors in hematopoietic differentiation and apoptosis," International Journal of Oncology, vol. 12, no. 3, pp. 685-700, 1998.

[76] A. M. Rampalli and P. S. Zelenka, "Insulin regulates expression of c-fos and c-jun and suppresses apoptosis of lens epithelial cells," Cell Growth and Differentiation-Publication American Association for Cancer Research, vol. 6, no. 8, pp. 945-953, 1995.

[77] X. Jin, T. Jia, R. Liu, and S. Xu, "The antagonistic effect of selenium on cadmium-induced apoptosis via PPAR- $\gamma / \mathrm{PI} 3 \mathrm{~K} / \mathrm{Akt}$ pathway in chicken pancreas," Journal of Hazardous Materials, vol. 357, pp. 355-362, 2018.

[78] Y. Han, M. Niu, L. An, and W. Li, "Upregulation of proinflammatory cytokines and $\mathrm{NO}$ production in $\mathrm{BV}$-activated avian macrophage-like cell line (HD11) requires MAPK and NFkappaB pathways," International Immunopharmacology, vol. 9, no. 7-8, pp. 817-823, 2009.

[79] M. Takagi, T. Takeda, Y. Asada, C. Sugimoto, M. Onuma, and K. Ohashi, "The presence of a short form of p53 in chicken lymphoblastoid cell lines during apoptosis," Journal of Veterinary Medical Science, vol. 68, no. 6, pp. 561-566, 2006. 


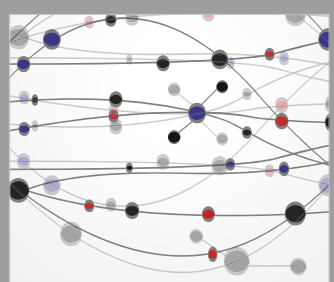

The Scientific World Journal
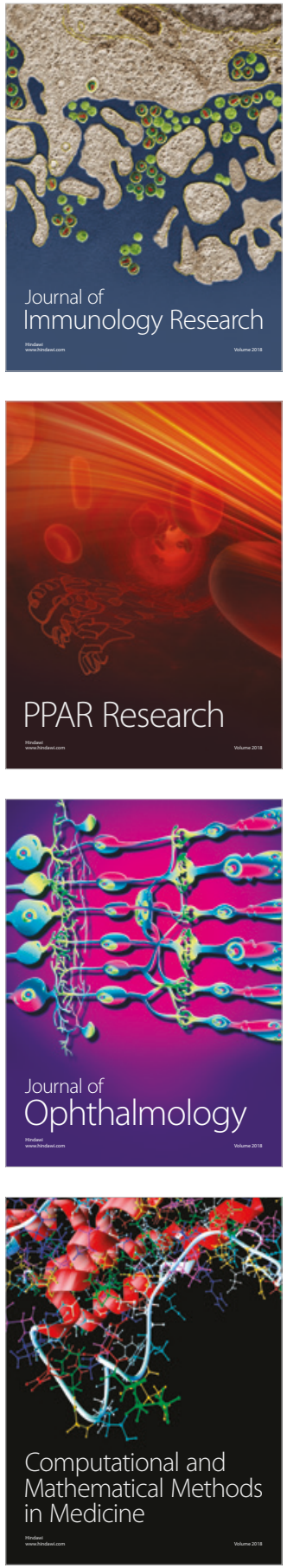

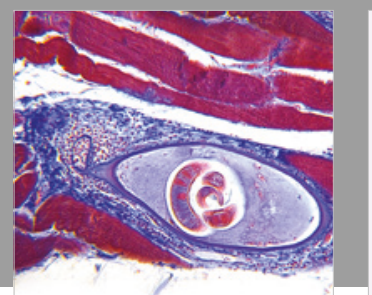

Gastroenterology Research and Practice

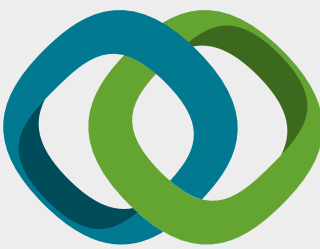

\section{Hindawi}

Submit your manuscripts at

www.hindawi.com
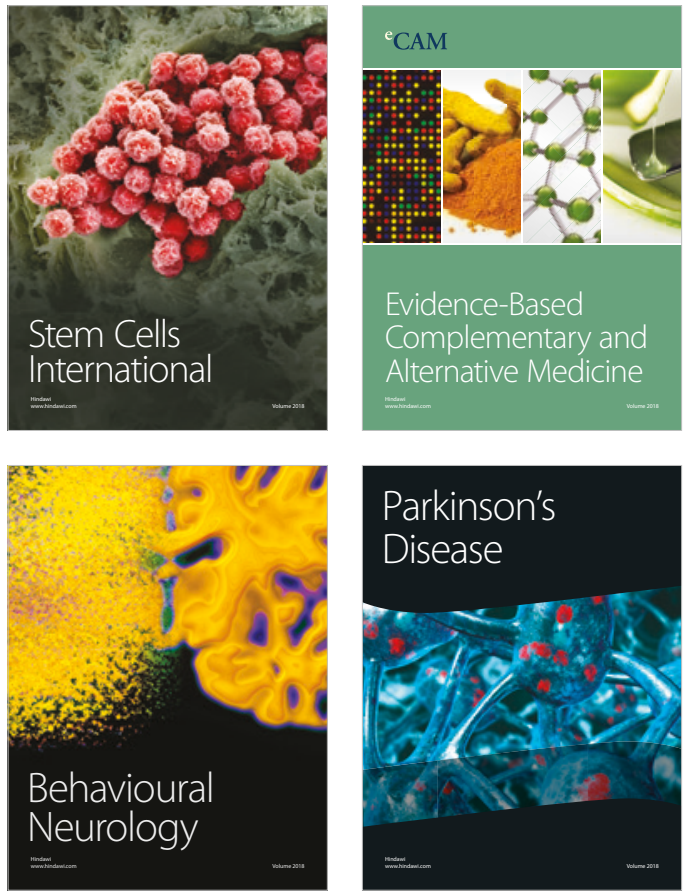

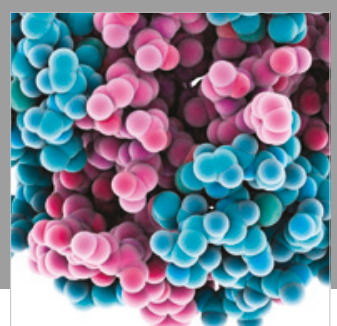

ournal of

Diabetes Research

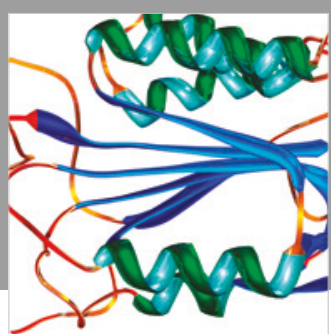

Disease Markers
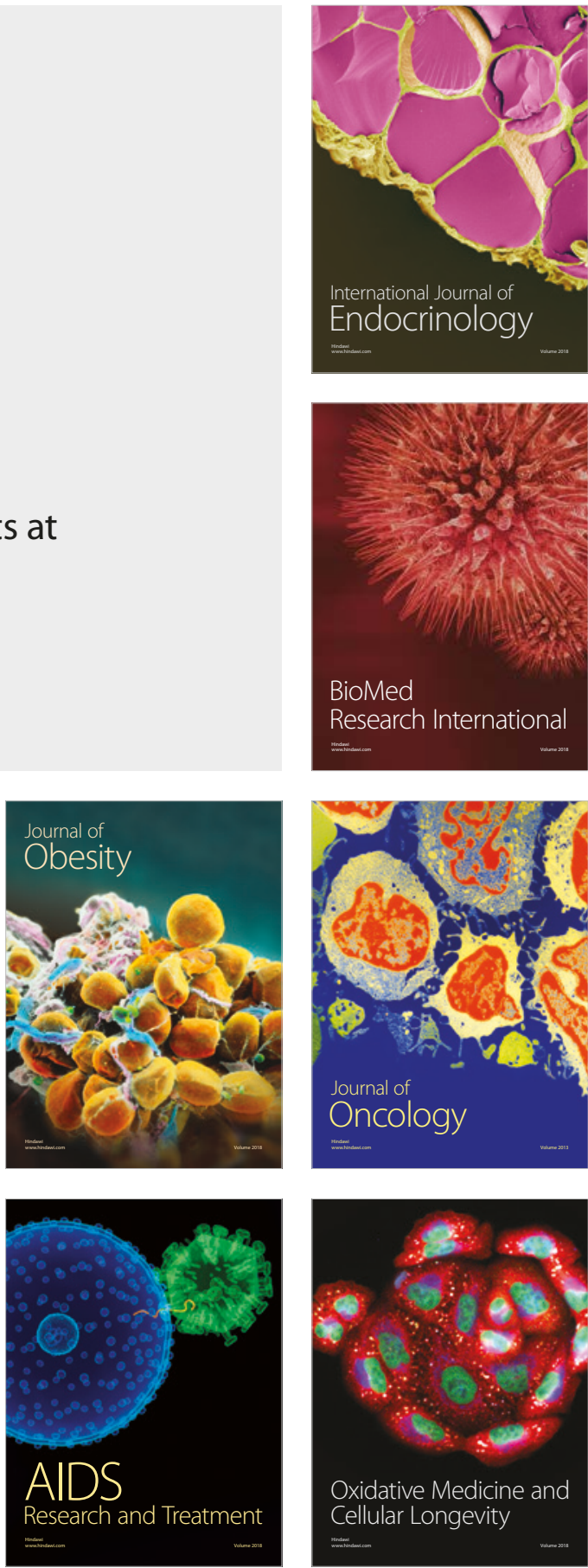